\title{
Optimal tuning of PI controller using genetic algorithm for wind turbine application
}

\author{
Yamina Belgaid', M'hamed Helaimi', Rachid Taleb $^{3}$, Mohammed Benali Youcef ${ }^{4}$ \\ 1,2,3 Electrical Engineering Department, Hassiba Benbouali University, LGEER Laboratory, Algeria \\ ${ }^{4}$ Electrical Engineering Department, USTO-MB University, Algeria
}

\section{Article Info \\ Article history: \\ Received Jun 14, 2019 \\ Revised Sep 15, 2019 \\ Accepted Oct 6, 2019}

\section{Keywords:}

Classical PI

Genetic algorithm

Genetical PI

Optimization by genetic

algorithms

Wind generator

\begin{abstract}
Nowadays, wind turbine energy has an increased importance in electrical power applications since when it is considered as an essential inexhaustible and broadly available energy resource. An aerogenerator is a device that transforms a part of the kinetic energy of the wind into available mechanical energy on a transmission shaft, and then into electrical energy through a generator, which is in our case a dual power asynchronous machine. An important characteristic of a wind turbine is that the avail, able maximum power is provided only in a single given operating point, called Maximum Power Point. Many classical methods and controllers have been widely developed and implemented to track the maximum power point. Among drawbacks of a classical PI controller is that its parameters are not constant, these conventional control laws may be are insufficient because they are not robust, especially when the accuracy requirements and other dynamic characteristics of the system are strict. The new idea in this paper is to introduce the Genetic Algorithms theory into the controlstrategy that used inthe conversion chain of the wind turbine, in order to improve stability. Simulation results approve that the application of Genetic Algorithms to the PI regulator, minimize or eliminate the drawbacks of the classical PI regulator, and greatly promote the efficiency and stability of the wind turbine systems.
\end{abstract}

Copyright $@ 2020$ Institute of Advanced Engineering and Science. All rights reserved.

\section{Corresponding Author:}

Yamina Belgaid,

Electrical Engineering Departement,

Laboratoire Génie Electrique et Energies Renouvelables (LGEER),

Hassiba Benbouali University, Chlef, Algeria.

Email: Belgaid.Ya@Gmail.Com

\section{INTRODUCTION}

For several years,traditional power generation plants cause various pollutions and ecological imbalance by using fossil and natural sources such as uranium, hydrocarbons, and water.For example, thermal power plants (coal, oil) are responsible for atmospheric emissions. Hydroelectric power stations sometimes require the construction of water reservoirs that radically alter the equilibrium of an entire area [1]. The degradation of air quality is considered as a major problem which has led authorities around the world to take measures to reduce pollutant emissions. As a result, the power generation industry is undertaking to adapt to these new constraints by promoting wind energy. Currently, several wind farms are installed in the world and are the only one that is both inexpensive and capable of mass production, Wind energy has a higher energy potential and becomes the first source of renewable energy after hydraulics [2]. Most variable speed wind turbine systems are equipped by the dual-powered asynchronous machine, this type of machine allows a wide range of speed variation $( \pm 30 \%)$ of the synchronism speed $[3,4]$. This is very useful to extract the maximum power during its operation. 
Wind turbines have a specific electrical characteristic of a non-linear nature and have a particular point called "Maximum Power Point". The purpose of any control in this domain is the permanent search for that's maximum, this technique is also widely used in photovoltaic systems $[5,6]$, where the MPPT's search in the current-voltage plan ultimately allows the cost of the $\mathrm{kWh}$ produced to be reduced. This power optimization occurs in zone 2 of the operating curve of a variable speed wind turbine. In recent decades, several advanced control methods have been developed to control the production processes of electrical energy. However, the performance of the control system has not always been assured due to the complexity of the control algorithms and the non-linearity characteristic of the systems to be controlled.

The Conventional PI control techniques cover a wide range of industrial applications; those techniques are linear and have the advantage of simple implementation and the non-complexity synthesis of regulators' gains. Inthe course of time, these applications have become less efficient, especially if the processes to be controlled have acomplex and non-linear structure. Finding an alternative to these conventional techniques is a persistent concern for many researchers because it involves a compromise between the robustness on one side and cost on the other. According to reference [7], classical PI controllers have some problems related to non-linear systems with non-constant parameters; the conventional control laws may be insufficient because they are not robust, especially when the requirements of accuracy and other dynamic characteristics of the systemto be controlled are strict. For this, we should use insensitive control laws to the disturbances and nonlinear cases. The main problem in this article is the calculation of the parameters of the classical PI regulator.

There is a call in the literature that encourages the improvement of crossover operators for more efficient optimization schemes of evolutionary algorithms. The influence of crossing operators is vital for the whole process of the genetic algorithm in the search for an optimal search space $[8,9]$. The novel idea of this article is to introduce the theory of genetic algorithms in the control strategy used in the wind turbine conversion chain to improve stabilityby itsapplying on the conventional PI.wherein our casethe genetic algorithm is used to search for an optimum PI regulatory gains. The simulation results confirm that the application of genetic algorithms on the PI regulatorseliminatestheirdisadvantages and greatlyfavours the efficiency and stability of wind turbines.

\section{WIND ENERGY CONVERSION CHAIN MODELING}

The overall wind turbine diagram connected to the grid is illustrated by Figure 1. The wind turbine captures the kinetic energy of the wind and converts it into a torque that turns the rotor blades. There are three factors determine the relationship between wind energy and the recovered mechanical energy by the rotor: the air density, the area swept by the rotor and the wind speed. The Air density and wind speed are climatological parameters that depend on the site [10].

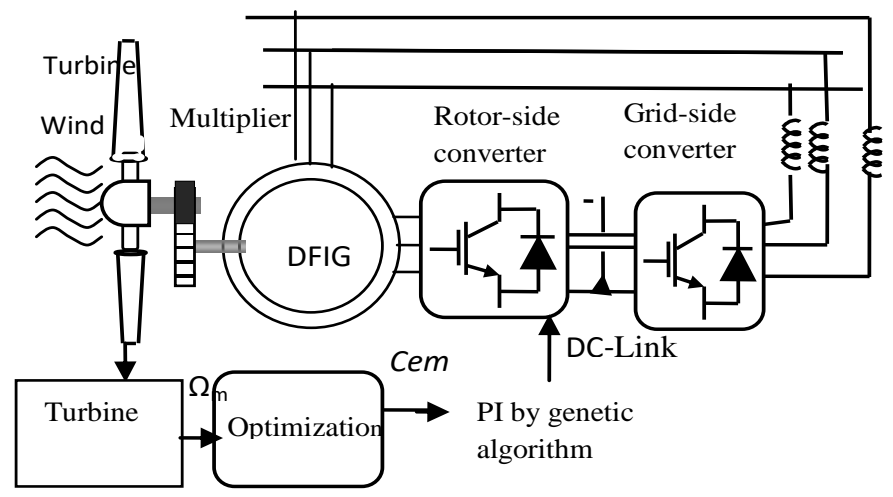

Figure 1. The control strategy principle

\subsection{Turbine Modeling}

The available wind power crossing a surface $S$ is defined by [11-12]:

$$
P_{v}=\frac{1}{2} \rho s_{V 1}^{3}
$$



[13-17]:

The available mechanical power depending on the generator speed for different wind speeds

$$
P_{m}=\frac{1}{2} C_{p}(\lambda) \rho s_{V 1}^{3}
$$

For the turbine that used in this study, the power coefficient is approximated by the following formula [18]:

$$
C_{p}(\lambda, \beta)=0.5\left(\frac{116}{\lambda_{i}}-0.4 \beta-5\right) \exp \left(\frac{-21}{\lambda_{i}}\right)+0.0068
$$

The speed ratio defined by:

$$
\lambda=\frac{\Omega_{\text {turbine }}}{V} R
$$

The dynamic fundamental equation makes it possible to determine the mechanical speed evolution of the asynchronous Generator. The simplified model of this equation is given by:

$$
J \frac{d \Omega_{m e c}}{d t}=C g-C e m-C v i s
$$

\section{OPTIMIZATION by GENETIC ALGORITHMS}

The Optimization is the search for the best solution to a problem in the sense of one or more selected criteria, respecting the characteristics of the system and the imposed constraints on it. The optimal solution is sought from a population of solutions by using random processes. The search for the best solution is carried out based on the creation of a new solutions generation, by the application of three operators successively; to the current population: the selection, the crossing, and the mutation. These operations are repeated until a stop criterion is reached [19]. A simple Genetic Algorithm principle is shown in Figure 2.

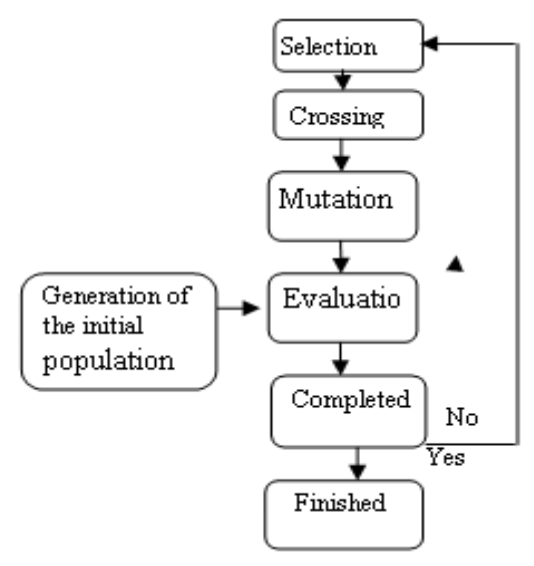

Figure 2. The general principle of genetic algorithm

The different stages of the simple Genetic Algorithm:

a) The initial population Creation.

b) The individual's Evaluation of the population.

c) The best individuals Selection.

d) Reproduction (crossing and mutation).

e) A new generation Formation. 


\section{GA APPLICATION to the PI REGULATOR OPTIMIZATION, for a WIND TURBINE \\ CONTROL}

In this part, we detail the implementation aspects of the PI parameters optimization by using GA. The aim is to find all the optimized parameters $\mathrm{P}=$ [KPopt, KIopt]. So that the system speed response of the closed-loop wind turbine is stable and as robust as possible for any variation of $\mathrm{J}_{\mathrm{t}}$ belonging to the gap. By using GA, it is possible to search for the optimal solution in a three-dimensional space, to the detriment of the quasi-one-dimensional search, which has been implemented from the iterative approach. Each one of the three-dimensional search space corresponds to the individual $\mathrm{x}$ variable of that we seek to optimize. The principle of the PI corrector optimization by using genetic algorithm as shown in Figure 3.

$$
\left[\mathrm{x}_{1 \text { in }}, \mathrm{x}_{1 \text { in }}\right]=\left[\mathrm{k}_{\mathrm{Pi}}, \mathrm{K}_{\mathrm{Ii}}\right]
$$

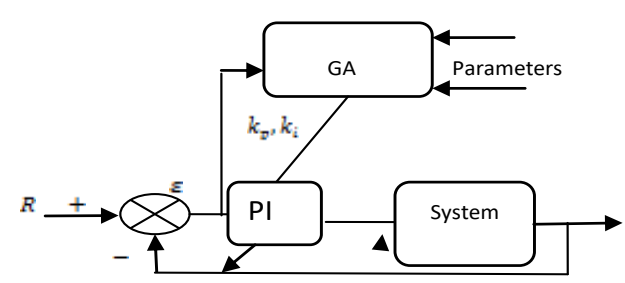

Figure 3.The principle of the PI corrector optimization by using genetic algorithm

In the same way, that we limited the uncertainty of the mechanical load inertia Jt according to the defined interval in the work, a region of space D limits the possible parameters values of the regulator PI, defined by the best coefficients for the Jmin terminals on the one hand and Jmax on the other hand. From some knowledge of the system to be regulated and the design of a PI type regulator, we can limit the search region of the optimal solution while ensuring the approach optimization, so that the GA convergence time is greatly reduced.

$$
D=\left[x_{1 i n}\right] *\left[x_{1 i n}\right]=\left[k_{p \min }{ }_{p \max }\right] *\left[k_{i \min } k_{i \max }\right]
$$

The approach optimization of the PI regulator by GA is defined in the following steps:

\subsection{Initial Population Definition}

The initial population is randomly selected in a solution search space. The variation interval of each variable of $\mathrm{D}$ is defined as follows:

\subsubsection{We Adopt The End Of The Variation Range Of Jl As A Reference For The System:}

$$
\begin{aligned}
& { }^{*} J_{t}=J_{i \min } \\
& { }^{k} J_{t}=J_{i \max }
\end{aligned}
$$

\subsubsection{For each reference of inertia}

we calculate from the control system simulations of a complete closed-loop wind turbine, the maximum values of each coefficient KP and KI by respecting the criterion of robustness and stability. As a result, we have two sets of controller parameters:
a) Together (1): $K_{P 1}, K_{I 1}$
b) Together (2): ${ }_{P 2}, K_{I 2}$

\subsubsection{The search space $D$ is defined by:}

$$
D=\left[0 \max \left(K_{P 1}, K_{P 2}\right)\right] *\left[0 \max \left(K_{I 1}, K_{I 2}\right)\right]
$$


The optimal values of the PI regulator are included in the search space D:

$$
\left\{\begin{array}{l}
x_{1 \text { opt }}=K_{\text {Popt }} \in\left[0 \max \left(K_{P 1}, K_{P 2}\right)\right] \\
x_{2 o p t}=K_{\text {Iopt }} \in\left[0 \max \left(K_{I 1}, K_{I 2}\right)\right]
\end{array}\right.
$$

\subsection{The Adaptation Function}

The integral inverse of the quadratic error between the reference speed of the mechanical load ${ }^{\omega}$ ref and the real speed $\omega$ is used as an adaptation function to maximize over an interval $\mathrm{T}$ :

$$
\begin{aligned}
f_{a d}\left(x_{1 i}, x_{2 i}\right) & =\frac{1}{1 / T \int_{0}^{T}\left(\omega_{r e f}-\omega\right)^{2} d t} \\
f_{a d}\left(x_{1 i}, x_{2 i}\right) & =\frac{1}{\sum_{\sum_{1 \max }} \frac{1}{T} \int_{0}^{T}\left(\omega_{r e f}-L^{-1}\left(H_{1-c}(p, n) * C_{e m}\right) d t\right.} \\
n & =J_{1 \min }{ }^{T}
\end{aligned}
$$

Where L-1 represents the inverse transformation of Laplace, and * represents a temporal convolution. The uncertain transfer function between the motor torque and the load speed $\mathrm{Hl}-\mathrm{c}$ (p, n) is given by:

$$
H_{1-c}(p, n)=\frac{1}{\left(f_{m}+f_{1}\right)\left[\frac{J_{m}^{n}}{K_{1}\left(f_{m}+f_{1}\right)} p^{3}+\left(\frac{f_{m} f_{1}+f_{m}^{n}}{K_{1}\left(f_{m}+f_{1}\right)} p^{3}+\left(\frac{\left(J_{m}+n\right) K_{1}+f_{m} f_{1}}{K_{1}\left(f_{m}+f_{1}\right)}\right) p+1\right]\right.}
$$

\subsection{The Selection Operator}

We use the standard geometric selection method which is a rank selection method based on a standardized geometric distribution. This method limits the probability of the best individual selection at the first generations beginning. With this method, the selection probability of the $i^{\text {th }}$

The individual in the population of $\operatorname{size}^{n} p$ is given by:

$$
p_{s}=\frac{q_{s}\left(1-q_{s}\right)^{r}-1}{1-\left(1-q_{s}\right)^{n} p}
$$

The rank of an individual is the index of the population in which it has been noticed as being dominated by no other individual. From the individuals set of a population, you take out those who are not dominated by any other individual, and you assign them to rank 1.On the individuals who did not stand out, you repeat the operation, looking for those who are not dominated by any remaining individuals and you assign them to rank2, and so on until the exhaustion of population. The best-judged individuals are those of the lowest rank.

\subsection{The Crossing Operator}

As part of our study, we use the arithmetic crossing. The crosses are considered with two individuals from the same population $\left(p_{a 1}, p_{a 2}\right)$, generally called fathers. As result of this crossing, we have two new individuals $\left(e_{1}, e_{2}\right)$, which are called sons. This type of crossing is defined as follows:

$$
\left\{\begin{array}{l}
e_{1}=p_{a 1} r_{c}+p_{a 2}\left(1-r_{c}\right) \\
e_{2}=p_{a 1}\left(1-r_{c}\right)+p_{a 2} r_{c}
\end{array}\right.
$$


Where ${ }^{r}$ is a random weighting variable between 0 and 1.The number of times that the arithmetic crossing must be applied to each generation is defined by the probability of crossing ${ }^{p}$.

\subsection{The Mutation Operator}

We use a real mutation with uniform type. Each individual of any population is changed according to a certain probability ${ }^{p} m$ by a random value, which is drawn following a uniform distribution over the interval of possible solutions D or the specific interval of mutation ${ }^{D_{m}}$.

\subsection{The Iteration}

The steps of the Genetic Algorithm (4.1) - (4.4) are executed until the moment while the adaptation function value of individuals no longer evolving, or when the maximum number of generations ${ }^{n} g$ is reached.

\section{WIND TURBINE SIMULATION}

All simulations were performed under MATLAB / SIMULINK software environment on a wind system. Two MPPT techniques were implemented in the simulation as controller; to study and compare the dynamic response of the wind system in terms of the variable wind speed evolution. These two control structures were simulated by considering an average wind profile around $(12.5 \mathrm{~m} / \mathrm{s})$ as shown in Figure 4 . We display the obtained results for the different control strategies used.The power coefficient performance of the turbine and the relative speed $(\lambda)$, the generator rotation speed as well as its reference and the turbine aerodynamic power. The proposed (PI-genetics) method and the classical-PI method are illustrated in Figures 5, 6, 7, and 8 .

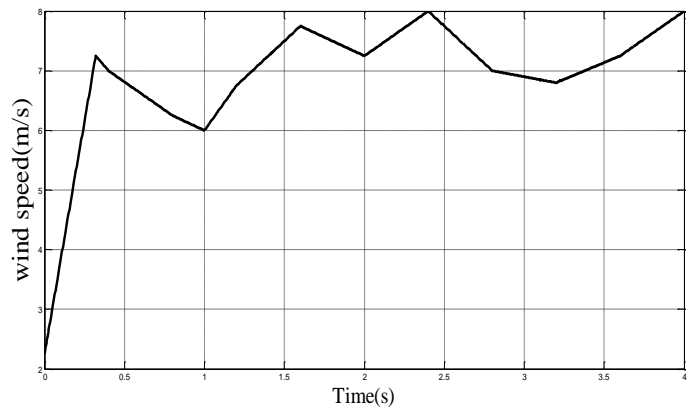

Figure 4. Applied wind profile

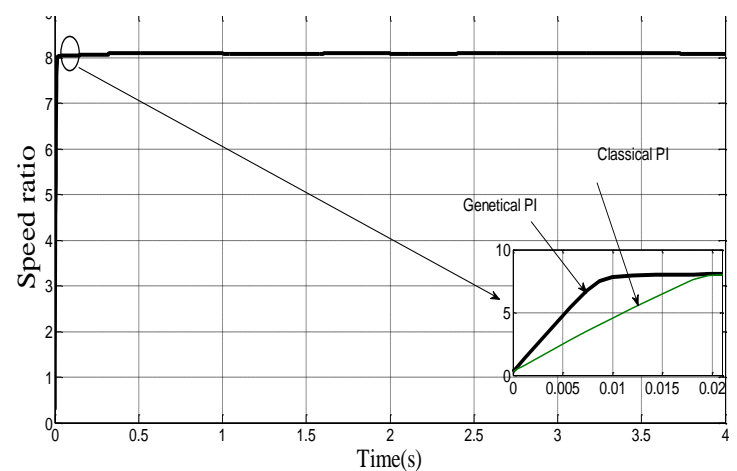

Figure 6. The relative speed $(\lambda)$

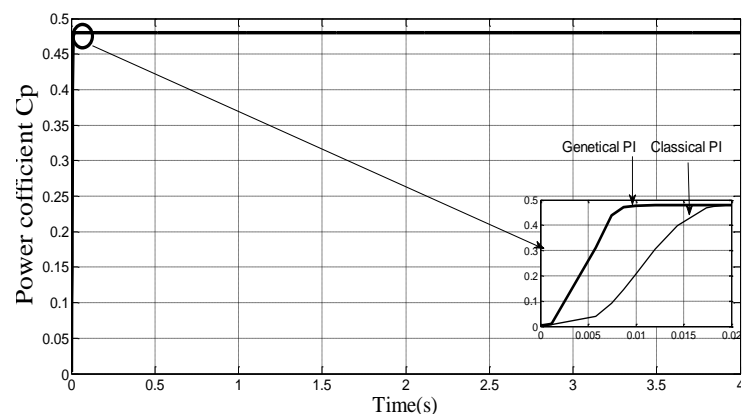

Figure 5. The turbine power coefficient

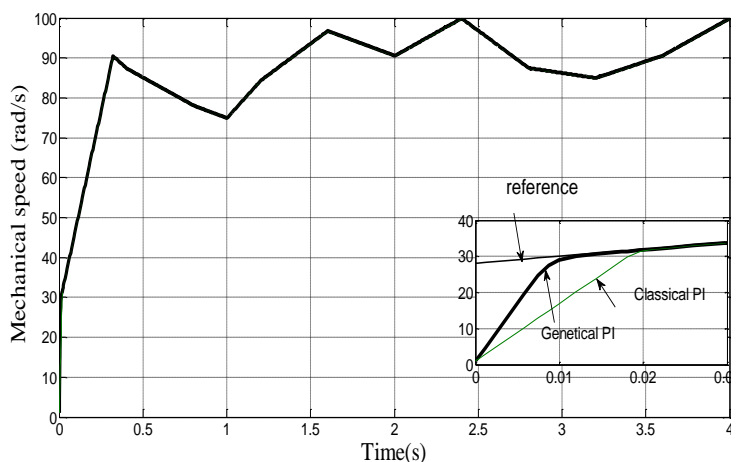

Figure 7. The generator rotational speed 


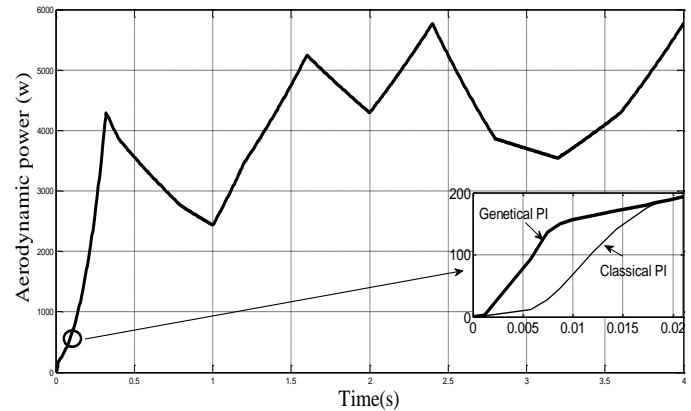

Figure 8. The turbine aerodynamic power

In Figure 5, we can see that the MPPT (PI-Genetics) can quickly converge to MPPT, the power factor of MMPT PI-Genetics could finally converge to MMPT at 10ms while the MPPT PI-classic converges towards MPPT at 20ms.It concluded that the PI-Genetic MPPT could faster track the MPPT than the MPPT PI-classic.

On the other hand, in the context of power factor stabilization, the MPPT PI-classic has suffered a significant loss and caused an oscillation around the MPPT, while the MPPT PI-Genetics also offers the possibility to eliminate the oscillation around the MPPT. We found that the efficiency of the systemwith MPPT PI-Genetics was greater than 99.97\%.Based on Figure 5 and Figure 7, it can be seen that PI-Genetics is able to reduce the speed and the disturbingpower after the wind turbine has been approached. From the obtained simulation results, the MPPT PI-Genetic has a better performance compared to the MPPT PI-classic.

\section{ELECTRICALCONVERSION CHAIN MODELING}

The chosen Generator for the wind energy transformation is the doubly fed induction generator (DFIG) [20, 21].Moreover, a DFIG is controlled by the rotor and is used with a speed variation range limitation $\pm 50 \%$ of the nominal speed.

The DFIG dynamic model in the reference dq which is related to the rotating field, is presented by (equation number), where ${ }^{V} d s,{ }_{q s},{ }{ }_{d r},{ }{ }_{q r},{ }^{i} d s,{ }^{i} q s,{ }^{i} d r,{ }^{i} q r$ are respectively the voltages and the currents at the output of the generator in the Park model [22-25].

$$
\left\{\begin{array}{l}
V_{d s}=R_{s} i_{d s}+\frac{d}{d t} \Phi_{d s}-\omega_{s} \phi_{q s} \\
V_{q s}=R_{s} i_{q s}+\frac{d}{d t} \phi_{q s}+\omega_{S} \phi_{d s} \\
V_{d r}=R_{r} i_{d r}+\frac{d}{d t} \phi_{d r}+\left(\omega_{S}-\omega\right) \phi d r \\
V_{q r}=R_{r} i_{q r}+\frac{d}{d t} \phi_{q r}-\left(\omega_{s}-\omega\right) \phi_{d r}
\end{array}\right.
$$

In addition, the flowing equations are expressed by:

$$
\left\{\begin{array}{l}
\phi_{d s}=L_{s} i_{d s}+M i_{d r} \\
\phi_{q s}=L_{s} i_{q s}+M i_{q s} \\
\phi_{d r}=L_{r} i_{q s}+M i_{d s} \\
\phi_{q r}=L_{r} i_{q r}+M i_{q s}
\end{array}\right.
$$

On the other hand, the electromagnetic torque equation is given by: 


$$
C_{e m}=\frac{3}{2} P \frac{M}{L_{s}}\left(\phi_{d s} i_{q r}-\phi_{q s} i_{d r}\right)
$$

The stator flux orientation allows the magnitudes decoupling of the two axes $\mathrm{d}$ and q. By orienting the stator flux along the axis d, we can write

$$
\varphi_{s q}=0, \varphi_{s}=\varphi_{s d}
$$

The electromagnetic torque is then written:

$$
C_{e m}=\frac{3}{2} p \frac{M}{L_{s}}\left(\phi_{d s}{ }^{i} d r\right)
$$

In addition, the flows equations become:

$$
\left\{\begin{array}{l}
\phi_{d s}=L_{s} i_{d s}+M i_{d r} \\
0=L_{s} i_{q s}+M i_{q r}
\end{array}\right.
$$

In the two-phase reference system, the active and reactive stator powers of an asynchronous generator are written:

$$
\left\{\begin{array}{l}
P=V_{d s}{ }^{i} d s+V_{q s} i^{q} \\
Q=V_{q s}{ }^{i} d s-V_{d s} i^{q}
\end{array}\right.
$$

The adaptation of these equations to the simplifying assumptions gives:

$$
\left\{\begin{array}{l}
P=-V_{S} \frac{M}{L_{S}} i_{d r} \\
Q=\frac{V_{S} \phi_{S}}{L_{S}}-\frac{V_{S} M}{L_{S}} i_{d r}
\end{array}\right.
$$

For the generator control, the established expressions showing the relationship between the rotor currents and voltages that will be applied to it

$$
\left\{\begin{array}{l}
V_{d r}=R_{r} i_{d r}-g \omega_{S}\left(L_{r}-\frac{M^{2}}{L_{S}}\right) i_{q r} \\
V_{q r}=R_{r} i_{q r}+g \omega_{S}\left(L_{r}-\frac{M^{2}}{L_{S}}\right) i_{d r}+g \omega_{S} \frac{M V_{S}}{\omega_{S} L_{s}}
\end{array}\right.
$$

\section{CONVERTERS and ELECTRICITY NETWORK MODEL}

The two converters interposed between the DFIG rotor and the network is the PWM type. The control signals will be determined by serving the DC bus voltage [26].

$$
\left[\begin{array}{c}
V_{d s} \\
V_{s q}
\end{array}\right]=\frac{{ }_{d c}}{2}\left[\begin{array}{c}
V_{w d 1} \\
V_{w q 1}
\end{array}\right]
$$




$$
\left[\begin{array}{c}
V_{m d} \\
V_{m q}
\end{array}\right]=\frac{V_{d c}}{2}\left[\begin{array}{c}
V_{w d 2} \\
V_{w d 2}
\end{array}\right]
$$

The voltage of the continuous bus $\mathrm{u}$ varies according to the power exchanging between the wind turbine and the network, it evolves according to the following equation:

$$
\frac{d V}{d t}=\frac{1}{C}\left[i_{1}-i_{r e s}\right]
$$

The power that should be circulated by the rotor converter AC / DC / AC in the hyper or hypo synchronous case is given by [27]:

$$
p_{r}=3 I V_{s}=g_{\max } p_{s}
$$

The DC bus voltage must check the following equation:

$$
V_{d c}=2 \alpha V_{s} \sqrt{2}
$$

\section{CONTROL of the SENT POWERS to the NETWORK}

The transited active and reactive powers are given as follows:

$$
\left\{\begin{array}{l}
P=V_{d r} i_{d r}+V_{q r} i_{q r} \\
Q=V_{q r} i_{d r}-V_{d r} i_{q r}
\end{array}\right.
$$

The currents on the grid side are envisaged by imposing references for the active and reactive power,

$$
\begin{gathered}
\left\{\begin{array}{c}
i_{d r-r e f}=\frac{p_{r e f} V_{d r-m e s}+Q_{r e f} V_{q r-m e s}}{V_{d r-m e s}^{2}+V_{q r-m e s}^{2}} \\
i_{q r-r e f}=\frac{P_{r e f} V_{q r-m e s}-Q_{r e f} V_{d r-m e s}}{V_{d r-m e s}^{2}+V_{q r-m e s}^{2}} \\
P_{r e f}=V_{d c} i^{i}-P_{r e g}
\end{array}\right. \\
\text { The reference power: }
\end{gathered}
$$

$$
P_{r e g}=C_{u}(s)\left(V_{d-r e f}-V_{d c}\right)
$$

\section{SIMULATION RESUTS and DISCUSSION}

All simulations were performed under MATLAB / SIMULINK software environment on a turbine system as shown in Figure 1.Two MPPT techniques are implemented in simulation as a controller, to study and compare the dynamic response of the turbine system. 
The reference of the reactive power $Q_{\text {ref }}$ is respectively set at $(5000 ; 0 ;-5000)$ VAR. The active power is fixed at $48 \%$ of the mechanical power of the wind turbine. The reference of the DC bus voltage is set at $150 \mathrm{~V}$.

The result of the control of the active power is presented in Figure 8, where it gives perfectly the image of the corrected and corrugated currents. The DC bus voltage control result is shown in Figure 10 where the measured voltage is identical to the reference. The reactive power control result is shown in Figure 9.

Between 0 and $1 \mathrm{~s}$, the system provides the reactive power $(\mathrm{Q}=5000 \mathrm{VAR})$; from 1 to $3 \mathrm{~s}$, the system has the unit power factor $(\mathrm{Q}=0)$ and from 3 to 4 s the system absorbs the reactive power $(\mathrm{Q}=$ 5000VAR).

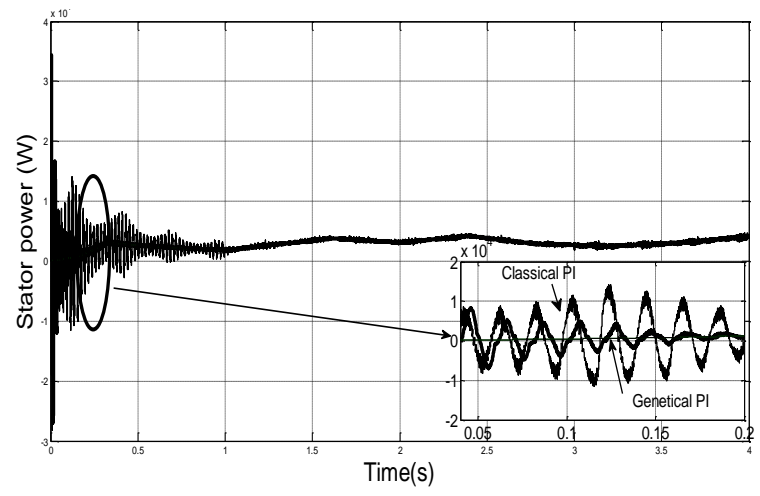

Figure 9. The active power of the stator

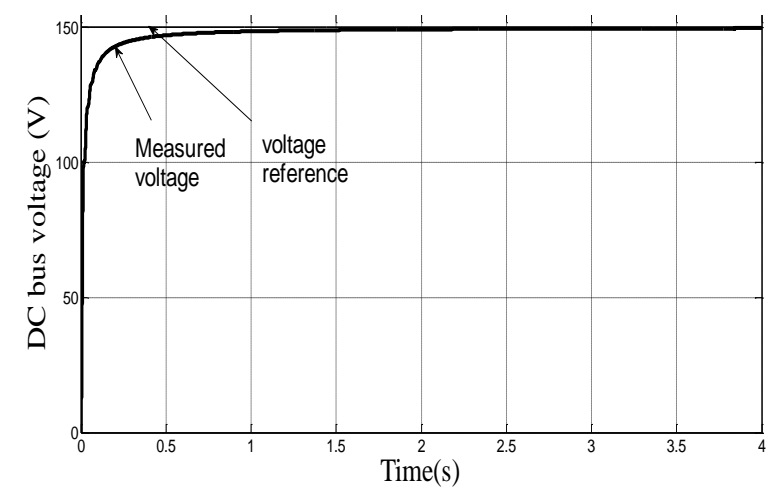

Figure 11. The continuous bus voltage

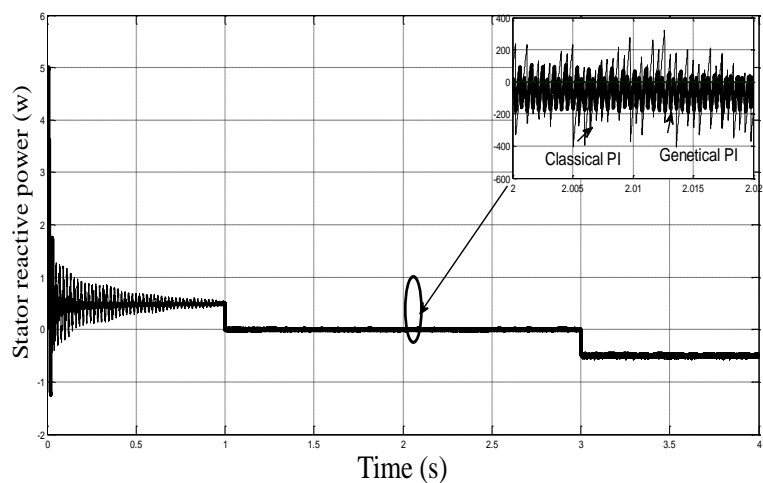

Figure 10. The reactive power of the stator

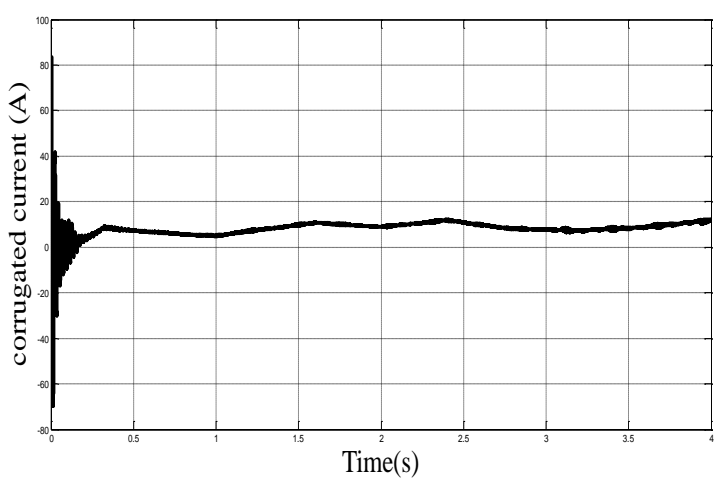

Figure 12. The measured current on the DC bus

\section{CONCLUSION}

This article proposes a new MPPT control for the wind energy generation using the Genetic Algorithm approach. To evaluate the effectiveness of this newest control, the MPPT Genetical PI performance was compared to the Classical PI. Finally, the MPPT Genetical PI can more quickly follow the MPPT and control the wind system for better performance in terms of power stability.

\section{REFERENCES}

[1] B. Robyns, et al., "Impact de L'éolien sur le Réseau de Transport et la Qualité de L'énergie,"J3eA, Vol. 5 - Hors Série 12006.

[2] L. P. a. K. Johnson,"Control of Wind Turbines," IEEE Control System Magazine.pp. 44 -61, 2011.

[3] A. Tanvir, et al., "Real-Time Control of Active and Reactive Power for Doubly Fed Induction Generator (DFIG)Based Wind Energy Conversion System," Energies, Vol.8, pp. 10389-10408, 2015. 
[4] G. 1. Yu, et al., "A Novel Two-Mode MPPT Control Algorithm Based on Comparative Study of Existing Algorithms," in Photovoltaic Specialists Conference, Conference Record of the Twenty-Ninth IEEE, pp. 1531-1534, 2002.

[5] F. Ansari, et al., "Control of MPPT for Photovoltaic Systems Using Advanced Algorithm EPP," in Power Systems and ICPS '09. International Conference on, pp. 1-6, 2009.

[6] M. Liserre, et al., "Of Multi-MW Wind Turbines and Wind Parks," IEEE Transactions of Industrial Electronics, Vol. 58, pp. 1081-1095, 2011.

[7] Y. Bekakra, et al., "Optimal Tuning of PI Controller using PSO Optimization for Indirect Power Control for DFIG based Wind Turbine with MPPT," International Journal of System Assurance Engineering and Management, Springer,Vol. 5, pp. 219-229, September 2014.

[8] A.J.P.Delima, et al., "A Modified Genetic Algorithm with a New Crossover Mating Scheme," Indonesian Journalof Electrical engineering and informatics, Vol. 7, pp. 165-181, June 2019.

[9] P. Błażej, et al., "The Role of Crossover Operator in Evolutionary-Based Approach to the Problem of Genetic Code Optimization," BioSystems, Vol. 150, pp. 61-72, 2016.

[10] F. Kendouli, et al., "Modélisation, Simulation et Contrôle d'une Turbine Eolienne à Vitesse Variable Basée sur la Génératrice Asynchrone à Double Alimentation," Revue des Energies Renouvelables Vol. 14, pp. 109-120, 2011.

[11] B.Beltran, et al., "Mode Power Control of Variable Speed Wind Energy Conversion Systems," IEEE Trans and Energy Conversion, Vol. 23, pp. 551-558, 2015.

[12] M. A. Ebrahim, "Towards Robust Non-Fragile Control in Wind Energy Engineering," Indonesian Journal of Electrical Engineering and Computer Science (IJEECS), Vol. 7, pp.29-42, July 2017.

[13] S. Taraft, et al., "Commande en Mode Glissant de la MADA dans une Eolienne à Vitesse Variable Connectée au Réseau," Revue des Energies Renouvelables SMEE'10 Bou Ismaïl Tipaza, pp.337-346,2010.

[14] F. Poitiers, "Etude et Commande de Génératrice Asynchrone pour l'Utilisation de l'Energie Eolienne," Thèse de Doctorat, Université de Nantes, Décembre 2003.

[15] G.A. Smith and K.A. Nigim, "Wind-Energy Recovery by a Static Scherbius Induction Generator," IEE Proceedings, Vol. 128, pp. 317-324, 1981.

[16] M. S. Nazir, et al., "Symmetrical Short Circuit Parameter Differences of Double Fed Induction Generator and Synchronous Generator Based Wind Turbine," Indonesian Journal of Electrical engineering and computer science(IJEECS), Vol. 6, pp. 268-277, May 2017.

[17] H.Li, et al., "Overview of different wind generator systems and their comparisons. IET Renew. Power Gener, Vol 2, pp.123-138, 2008.

[18] A. Moualdia, et al., "Direct Torque Control of the DFIG and Direct Power Control for Grid Side Converter in wind power generation system," The Mediterranean Journal of measurement and control, Vol. 9, pp. 101-108, 2013.

[19] R. Asgharian, "Asymptomatic Approach to Performance Weights Selection in Design of Robust HœPSS Using Genetic Algorithms," IEEE Trans and on EC, Vol. 11, pp.111-117, September 1996.

[20] A.tabia, "Modeling and Control of a Wind Turbine Driven Doubly Fed Induction Generator," IEEE Trans and Energy Conversion, Vol. 18, pp.194-204, 2003.

[21] M.Arifujjaman, "Vector Control of a DFIG Based Wind Turbine," Journal of Electrical \& Electronics Engineering, Istambul, Vol. 9, pp.1057-1065, 2009.

[22] B.Bouchafaa, et al., "Enslavement and Control in dq Inverter NPC,"Archives of Control Sciences, Vol.18, pp. 497-513, Décembre, 2008.

[23] S. Müller et al., "Doubly Fed Induction Generator Systems," IEEE Industry Applications Magazine, Vol. 8, pp. 26-33, May-June 2002.

[24] L.Xu, et al., "Direct Active and Reactive Power Control of DFIG for Wind Energy Generation," IEEE Trans and Energy Convers, Vol 21, pp.750-758, 2006.

[25] F.Abdoune, L et al., "Terminal voltage build-up and control of a DFIG based stand-alone wind energy conversion system," Renew. Energy, Vol 97, pp.468-480, 2016.

[26] K.K. Mun, "Optimal Control and Operation Strategy for Wind Turbines Contributing to Grid Primary Frequency Regulation," Applied sciences, $\mathrm{Vol}$ 7, pp. 927,2017.

[27] B.Srinivasarao et al.,"A Neuro-Fuzzy Controller for Compensation of Voltage Disturbance in SMIB System," Electrical Engineering and Computer Science, Vol. 5, pp.72-80, January 2017.

\section{BIOGRAPHIES OF AUTHORS}

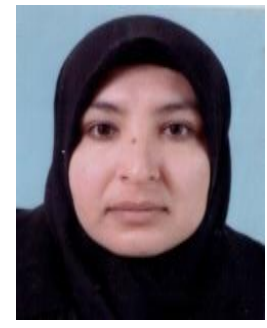

Yamina BELGAID Received the Engineer Degree and the Magister Degree, in Electrical Engineering from the University of Chlef, Algeria, in 2007 and 2011, respectively. Currently she is a professor with the Department of Electrical Engineering, Hassiba Benbouali University, Algeria. Her research interest includes renewable energy, Linear and Nonlinear control and robust control, Genetic Algorithm, heuristic optimization. 
Table 1. Wind Energy Conversion System Parameters Used

\begin{tabular}{lc}
\hline \multicolumn{1}{c}{ Parameter } & Nominal value \\
\hline \multicolumn{1}{c}{$R$} & $3.5 \mathrm{~m}$ \\
total inertia $J$ & $0.3125 \mathrm{~kg} . \mathrm{m} 2$ \\
Coefficient viscous $f_{v}$ & 0.00681 \\
Multiplier G & 5.4 \\
Power $P_{n}$ & $7.5 \mathrm{KW}$ \\
Effective stator voltage $V_{n}$ & $220 \mathrm{~V}$ \\
Stator frequency $f$ & $50 \mathrm{~Hz}$ \\
stator resistor $R_{s}$ & $0.455 \Omega$ \\
rotor resistor $R_{r}$ & $0.62 \Omega$ \\
magnetizing inductance & $0.078 \mathrm{H}$ \\
stator inductors & $0.048 \mathrm{H}$ \\
rotor inductors & $0.081 \mathrm{H}$ \\
population size & 50 \\
Number of variables & 2 \\
probability of mutation & $5 \%$ \\
Number of generation & 50 \\
\hline
\end{tabular}
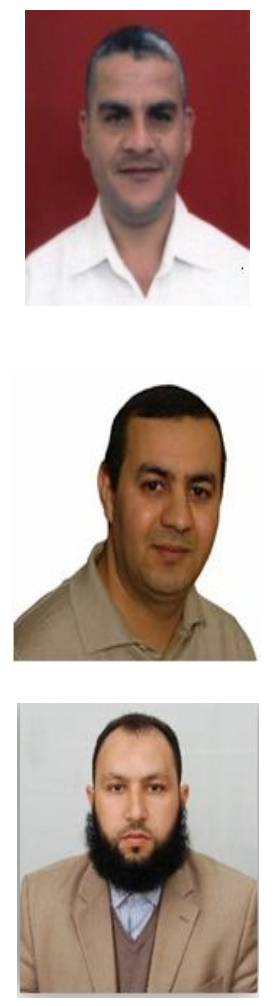

Mohammed BENALI YOUCEF Was born in 1984 in Chlef, Algeria. He received the Engineer and magister degrees in Electrical engineering from University of Chlef, Algeria, in 2003 and 2012, respectively. He is with the Process Control Laboratory, University of Oran, Algeria. His research interests are in Electrical Machines and Control.

M'hamed HELAIMI Received the Engineer Degree (with honors) and the Magister Degree, in Electrical Engineering from the University of Chlef, Algeria, in 2001 and 2004, respectively. In 2004, He joined the Department of Electrical Engineering, University of Chlef, where, from 2004 to 2014, He was a research assistant. He received the Ph.D. degree in Electrical Engineering from the University of Sciences and technology of Oran, Algeria, in 2014. He is Researcher member in the Laboratory of Electrical Engineering and Renewable Energy since 2011. His scientific work is related to induction heating application and drives, Genetic Algorithm, Artificial intelligence, non linear control, dynamic modeling, DSP processor, FPGA and Power Electronics.

Rachid TALEB Received the M.S. degree in electrical engineering from the Hassiba Benbouali University, Chlef, Algeria, in 2004 and the Ph.D. degree in electrical engineering from the Djillali Liabes University, Sidi Bel-Abbes, Algeria, in 2011. Currently he is a professor with the Department of Electrical Engineering, Hassiba Benbouali University. He is a team leader in the LGEER Laboratory (Laboratoire Génie Electrique et Energies Renouvelables). His research interest includes intelligent control, heuristic optimization, control theory of converters and converters for renewable energy sources.

\section{APPENDIX}

